\title{
A PROVA FORMATIVA NA EDUCAÇÃO SUPERIOR: POSSIBILIDADE DE REGULAÇÃO E AUTORREGULAÇÃO
}

DIRCE APARECIDA FOLETTO DE MORAES

\section{RESUMO}

Este artigo tem como propósito principal relatar os resultados da investigação sobre as possibilidades do uso da prova como instrumento de avaliação formativa em um curso de formação de professores na tentativa de superar sua visão classificatória da prova. Nesses cursos, faz-se necessário vivenciar experiências que ajudem os sujeitos a entender a utilização dos instrumentos avaliativos em uma perspectiva formativa capaz de subsidiar a regulação e a autorregulação dos processos de ensino e aprendizagem, distanciando-se da função de apenas verificar o que foi aprendido e dar uma nota. A pesquisa focou a prática de uma prova em sua função formativa, servindo tanto ao professor como aos alunos para repensar e modificar suas ações. Os resultados apontaram que, quando se compreende o significado da avaliação em sua função formativa, a visão classificatória pode ser superada e uma nova concepção de avaliação constituída.

PALAVRAS-CHAVE AVALIAÇÃO FORMATIVA • PROVA • FORMAÇÃO DE PROFESSORES - AVALIAÇÃO ESCOLAR. 


\section{RESUMEN}

Este artículo tiene como principal propósito relatar los resultados de la investigación sobre las posibilidades del uso de la prueba como instrumento de evaluación formativa en un curso de formación de profesores, en el intento de superar su visión clasificatoria de la misma. En dichos cursos se hace necesario vivenciar experiencias que ayuden los sujetos a entender la utilización de los instrumentos de evaluación desde una perspectiva formativa capaz de subsidiar la regulación y la autorregulación de los procesos de enseñanza y aprendizaje, alejándose de la función de tan sólo verificar lo que se aprendió y darle una nota. El estudio abordó la práctica de una prueba en su función formativa, sirviendo tanto al profesor como a los alumnos para repensar y modificar sus acciones. Los resultados señalaron que cuando se comprende el significado de la evaluación en su función formativa, se puede superar la visión clasificatoria y constituir una nueva concepción de evaluación.

PALABRAS CLAVE EVALUACIÓN FORMATIVA - PRUEBA • FORMACIÓN DE PROFESORES • EVALUACIÓN ESCOLAR.

\section{ABSTRACT}

The main purpose of this article is to report the results of the investigation into the possibilities of using testing as a formative evaluation instrument, in a teacher training program in an attempt to overcome their classificatory view of testing. In these programs, it is necessary to have lived the experiences that will help the subjects to understand the use of evaluative instruments from a formative point of view. This supports regulation and self-regulation of the processes of teaching and learning, moving away from the function of only verifying what was learned and assigning a grade. This study focused on the formative function of testing, serving both the teacher and the students in rethinking and modifying their actions. The results indicate that when one understands the meaning of evaluation as a formative function, the classificatory point of view may be overcome and a new concept of evaluation formed. 


\section{INTRODUÇÃO}

$\mathrm{Na}$ tentativa de superar a visão quantitativa da avaliação da aprendizagem, estudos relacionados ao tema vêm sendo realizados com a finalidade de propor uma avaliação de caráter mais pedagógico e que se distancie do exercício classificatório. Porém, mesmo ganhando repercussão no discurso teórico, o qual defende a necessidade de compreensão e de superação de paradigmas conservadores, na prática, a avaliação da aprendizagem ainda é vista como uma função burocrática a ser cumprida, seja na educação básica seja na superior, visto que "uma grande parte de escolas e docentes estimam que avaliam os alunos porque têm de informar mais do que por qualquer outra razão do tipo pedagógico” (SACRISTÁN, 2000, p. 296).

Tal realidade se amplia ainda mais quando se refere à educação superior, porque "pela tradição dos cursos universitários, a avaliação traz consigo a ideia de nota, de poder, de aprovação ou reprovação, de autoridade, de classificação de alunos para os mais diversos fins" (MASETTO, 2003, p. 148). Por essas e outras razões, é possível perceber que, na atualidade, 
[...] a crítica à ineficácia dos processos de avaliação da aprendizagem universitária tem crescido e o esforço de oferecer alternativas mais consistentes e fecundas do ponto de vista pedagógico tem levado educadores a experimentarem novos formatos de avaliação, capazes de produzir e captar os avanços dos estudantes, tornando-os como tradutores da qualidade do trabalho pedagógico executado. (SORDI; SILVA, 2010, p. 943)

Dessa forma, "a avaliação, definida como instrumento de aprendizado, coloca-se em posição nova, apresentando-se com pressupostos e características intimamente ligadas aos objetivos educacionais e à missão da universidade" (COIMBRA, 2002, p. 75), ou seja, seu papel é o de acompanhar as ações dos atores do processo para que as aprendizagens sejam edificadas. Para que tal intento seja colocado em prática, no entanto, é preciso compreender e refletir sobre o significado da avaliação da aprendizagem na educação superior e sobre os instrumentos avaliativos, principalmente no que se refere a um curso de formação de professores, o qual deve ter o olhar e os objetivos voltados para a compreensão dos significados da avaliação no contexto escolar, nos aspectos teóricos e práticos.

Em relação aos instrumentos, entende-se que, se estes se prestam apenas à constatação e à atribuição de nota, em nada colaboram com o que é proposto pelo currículo, uma vez que não servem para repensar a prática pedagógica ou os caminhos que precisam ser percorridos para a superação das dificuldades de aprendizagem, nem mesmo ajudam no desenvolvimento da autonomia e de um pensamento mais crítico do discente, um dos pressupostos da educação superior.

Assim, ao tomar como base a necessidade de investigar as diferentes possibilidades de fazer uso da prova a serviço do processo de ensino e aprendizagem, distanciando-a do caráter classificatório e de contribuir para o repensar das políticas de formação inicial e continuada de professores no tocante a esse tema, entende-se como necessário clarificar os caminhos percorridos para que tal prática se efetive na educação superior. Para tanto, foi realizado um estudo que pretendeu aproximar o uso de tal instrumento avaliativo do 
sentido formativo em um curso de formação inicial de professores em seus aspectos teóricos e práticos.

\section{AVALIAR A APRENDIZAGEM UTILIZANDO A PROVA COMO FERRAMENTA FORMATIVA}

A ação de usar a avaliação somente para dar nota e verificar o que o aluno aprendeu ou não e seguir adiante sem refletir e tomar decisões acerca dos dados coletados caracteriza a avaliação como um ato isolado. É necessário entender que ela não se limita apenas à tarefa de medir os conhecimentos adquiridos pelos alunos, mas

[...] circunscrita ao foco pedagógico e da formação profissional, a avaliação deve atingir as ações do professor em sala de aula, no tocante aos métodos pedagógicos e às sequências das ações pedagógicas, bem como ao desempenho escolar do estudante, com vistas ao seu perfil profissional e ao seu nível de autonomia nos campos do saber e nas atitudes e competências requeridas pelo mundo do trabalho. (COIMBRA, 2002, p. 75)

Para que a avaliação seja um fator colaborador, contribuindo com a apropriação de saberes de maneira significativa, a sua função vai além de constatar, verificar ou medir, pois tem "o objetivo legítimo de contribuir para o êxito do ensino, isto é, para a construção desses saberes e competências pelos alunos" (HADJI, 2001, p. 15). Só assim poderá ajudar o professor a mapear as dificuldades e necessidades reais de seus educandos, bem como verificar os objetivos não atingidos e propor as melhores intervenções. Propicia, ainda, ao próprio estudante, informações importantes sobre o que já aprendeu e as condições reais do seu aprendizado, assim como os caminhos que precisa percorrer para superar as dificuldades e avançar nesse processo.

Essa perspectiva de avaliação é entendida por muitos teóricos (ALLAL, 1986; CARDINET, 1993; PERRENOUD, 1999; HADJI, 2001; ÁLVAREZ MÉNDEZ, 2002; JORBA; SANMARTÍ, 2003; FERNANDES, 2009; SANMARTÍ, 2009) como formativa por ter como função primordial regular o processo de 
ensino e de aprendizagem. Regular a aprendizagem significa utilizar-se das informações coletadas na avaliação para agir de forma diferenciada a fim de que o aluno não fique em defasagem nesse processo. É uma ação diferenciada, é ensinar de novo, replanejar o ensino de forma diferente, objetivando promover a aprendizagem. "Essa modalidade de avaliação reduz o fracasso que pode ocorrer pelo uso de uma avaliação de fins apenas somativos, quando não há mais tempo para melhorias" (DEPRESBÍTERES; TAVARES, 2009, p. 51).

Assim como Hadji (2001), Perrenoud (1999) considera formativa toda avaliação que tem como objetivo regular a aprendizagem do aluno e fornecer informações importantes, tornando-se um instrumento informativo a serviço do processo de ensino e de aprendizagem. Dessa forma, a compreensão que se tem da avaliação e a maneira de se utilizar os instrumentos é que a tornarão formativa, e não o instrumento em si. Entende-se que é possível fazer uso da prova de maneira formativa, desde que se tenha a intencionalidade e se saiba utilizá-la nessa perspectiva, sem confundi-la com a avaliação para classificar e certificar.

Uma prova formativa caracteriza-se por auxiliar os atores a compreenderem a realidade e pensarem em alternativas concretas para a superação dos obstáculos encontrados no caminho, possibilitando ao estudante o exercício da autoavaliação e da autorregulação, e, ao professor, o replanejamento da sua prática.

Essa parece uma tarefa difícil a ser concretizada, uma vez que a maneira como a prova vem sendo utilizada reforça a prática de um ensino descontextualizado, estático e de uma aprendizagem que privilegia a memorização e a reprodução, desprezando o exercício do pensamento, limitando-se ao papel de medida ao simplesmente aferir a aprendizagem do aluno em um determinado conteúdo. Essa é, muitas vezes, "realizada sem critérios, sem articulação entre os objetivos, os conteúdos e as estratégias de ensino. Tal prática resulta em um ato terminal e, portanto, sem continuidade após a constatação dos seus resultados" (MORAES, 2008, p. 82).

Por essas e outras razões, a prova recebe críticas de vários autores, como Afonso (2005), Hadji (1994, 2001), Luckesi (2002) 
e Álvarez Mendez, (2002), por entenderem que ela está a serviço da seleção e da exclusão social e que não há valor pedagógico quando, por exemplo, utiliza-se a prova de "múltipla escolha ou de completar espaços em branco para avaliar o domínio de conteúdos de um curso e poder assim qualificar o estudante. A maioria dessas provas avalia somente os níveis mais baixos de aprendizagem" (QUINTANA, 2003, p. 164). Outra crítica é com relação a utilização de provas com "enunciados pouco elucidativos, cobrança de conteúdos não significativos, propensão a 'pegadinhas', grande quantidade de questões em uma só prova e falta de clareza das finalidades do instrumento" (DEPRESBÍTERES; TAVARES, 2009, p. 59).

Essa prova é entendida como um "modo rudimentar", que tem como propósito apenas valorizar "se os alunos são bons receptores e bons memorizadores, porém nunca se são críticos ou criadores; se são capazes de aplicar os conhecimentos que adquirem e como os dominam" (ÁLVAREZ MÉNDEZ, 2002, p. 103). Isso ocorre porque muitos entendem a prova como um instrumento capaz de mensurar com precisão o desempenho e o esforço e, para isso, o aluno, muitas vezes, fica limitado a somente ter que "provar" o que aprendeu sem possibilidades de errar ou de perceber que há fragilidades em sua aprendizagem que precisam ser alteradas. Para superar essa concepção e se tornar formativa, a prova deve ser constituída de um instrumento capaz de fornecer aos professores e alunos informações importantes sobre a aprendizagem, evidenciando as falhas do percurso não alcançado, bem como o que pode ser feito para que todos realmente aprendam.

É claro que não se almeja defender o uso da prova como única ferramenta para avaliar a aprendizagem, já que é sabido que a prova não deve ser utilizada como singular e mais importante procedimento de avaliação; o que se pretende, porém, é explicitar que o problema não reside exatamente na prova, mas no uso que se faz dela, porque se ela "só serve como recurso para medir, sinônimo de qualificar a informação transmitida que o aluno pode reproduzir linearmente, $o$ artefato exame serve para poucos, educativamente falando" (ÁLVARES MÉNDEZ, 2002, p. 103). 
Em contrapartida, se bem utilizada, a "prova formativa pode rever todos os pré-requisitos de uma aprendizagem já realizada e levar a exercícios de recuperação no caso de surgirem falhas" (CARDINET, 1993, p. 41). Em outras palavras, configura-se como ferramenta auxiliar na tarefa de regular o ensino e as aprendizagens e na construção de novos saberes.

Para que a prova seja considerada formativa e possa contribuir para a regulação do ensino e da aprendizagem, ela precisa de uma intencionalidade diferenciada em cada etapa a ser cumprida que envolva o antes, o durante e o depois de sua realização. $O$ antes se refere à elaboração da prova: pensar no propósito de cada questão elaborada é um dos pré-requisitos em uma prova considerada formativa, tendo em vista a importância de se centrar em conteúdos considerados relevantes e não periféricos. Outra consideração refere-se ao fato de que as questões devem ser contextualizadas, desafiadoras, relevantes e adequadas à forma de ensino e ao nível da turma, possibilitando ao aluno expressar sua aprendizagem e aprender mais com a realização de tal exercício.

Nesse caso, é importante que sejam evitados alguns termos nos enunciados como: "sempre", "nunca", "jamais", "invariavelmente", "em sua opinião", "o que poderia ser dito em relação a”, bem como o uso de negativas. Essas são perguntas que constam de provas e que muitas vezes acabam conduzindo o estudante a respostas prontas, sem necessidade de reflexão, explicação ou argumentação. Essa forma de questão valoriza apenas aquele aluno que tem facilidade na memorização e não permite que o docente identifique se ele realmente aprendeu ou se apenas decorou.

Na elaboração de uma questão, é fundamental, mesmo na educação superior, evidenciar os critérios, pois isso favorece ao aluno entender o caminho que ele deve percorrer para responder tal questão, contribui para que a correção volte-se aos aspectos centrais dos conteúdos, ainda que não sejam alterados em função das respostas. O ideal é que os alunos tenham clareza dos critérios estabelecidos pelo professor e desenvolvam condições de operar uma imagem mental sobre o que representam, visto que "os estudantes que obtêm os melhores resultados são aqueles que sabem intuir as intenções dos 
professores e as suas exigências" (JORBA; SANMARTÍ, 2003, p. 38). Os critérios auxiliam o professor a ter certeza do que deve ser apresentado em cada resposta, porém é importante levar em consideração a compreensão do estudante, e não apenas a resposta decorada, a qual pode não representar sua real compreensão e aprendizagem (MORAES, 2011).

Vale ressaltar também que a diversificação dos tipos de itens que a prova contempla é um fator importante porque, se o docente fizer uso de apenas uma forma de questão, poderá privilegiar somente uma parte dos seus discentes, prejudicando os demais. Outros cuidados em relação à montagem da prova são considerados como imprescindíveis por Depresbíteres e Tavares: elaborar a prova com antecedência, rever a redação em termos gramaticais, verificar a apresentação gráfica e estética, adequar a organização das questões, “dar orientações gerais de como a prova será resolvida [...] zelar para não elaborar itens com conteúdos demasiadamente específicos não relevantes para a formação do aluno" (2009, p. 88-90). As autoras também enfatizam como necessário "evitar questões que possam ser respondidas com base em conhecimentos do cotidiano" $(2009$, p. 90$)$ e adequar a prova ao tempo disponível para sua execução.

Em se tratando de uma prova formativa, a atenção recai sobre a aprendizagem dos alunos durante o processo de correção. Em relação a isso, Álvarez Méndez (2002, p. 113) apresenta como fator relevante a

[...] clareza da informação que é dada aos alunos sobre a correção [...] com o intuito de que quem aprende melhore seu aproveitamento, avance em seu desenvolvimento pessoal e enriqueça o seu processo de aprendizagem.

Por essas razões, a correção da prova refere-se à etapa central da realização da prova, sendo um momento que precisa de uma atenção especial, visto que sua tarefa não consiste apenas em apontar erros e acertos, mas em levantar dados que permitam analisar as respostas com a finalidade de entender os caminhos que seu aluno percorreu e o seu significado para posteriores alterações no processo pedagógico docente e discente. 
Um aspecto importante em uma prova formativa são as anotações que o professor realiza na prova com o intuito de ajudar o aluno a tomar consciência dos seus erros e perceber as fragilidades da sua aprendizagem. Isso também pode ser entendido como feedback. Não é, no entanto, um simples retorno comprobatório do sucesso ou do fracasso, mas apontamentos que indicam ao aluno suas reais dificuldades e o que precisa fazer para acertar, avançar e melhorar sob o olhar do professor diante dos objetivos propostos. Assim, possibilitará condições ao discente para se autoavaliar e buscar estratégias de autorregulação. Porém, entregar a prova sem observações não favorece ao aluno o repensar sobre seu processo. Sobre isso, Sanmartí expressa:

[...] quando os professores desenvolvem sistematicamente os trabalhos com comentários sobre os acertos e os aspectos que podem ser melhorados, sem pontuá-los, os resultados dos estudantes melhoram, enquanto que, quando as provas Ihes são devolvidas apenas com uma nota, não há nenhuma mudança. (SANMARTí, 2009, p. 30-31)

Outro aspecto importante ao se tratar de uma prova formativa refere-se ao significado do erro compreendido por alunos e professores. No dicionário, o conceito apresenta-se como equívoco, engano, tendo, em relação ao processo avaliativo, um valor negativo e sendo entendido como sinônimo de fracasso ou incompetência que revela um "não saber". A prova, quando tradicionalmente utilizada, revela com veracidade tal definição do erro, atestando ao sujeito sua incapacidade e falta de conhecimento, e favorece a "criação de hierarquia de excelência” (PERRENOUD, 1999, p. 29).

No entanto, em uma perspectiva de avaliação preocupada com o ensino e com a aprendizagem, o erro passa a ser conceituado de forma diferente, sendo entendido como

[...] momento do processo de construção do conhecimento que dá pistas sobre o modo como cada um está organizando seu pensamento, a forma como está articulando seus diversos saberes, as diversas lógicas que atravessam a dinâmica ensino/aprendizagem, as muitas possibilidades de interpretação dos fatos, a existência de vários percursos, 
Assim, a compreensão do significado dos erros muda totalmente no tocante à prática de uma prova formativa. Eles passam a ser entendidos como "objeto de estudo, pois revelam a natureza das representações ou estratégias elaboradas pelos estudantes" (JORBA; SANMARTÍ, 2003, p. 30). Como objeto de estudo, o erro precisa ser analisado, e essa análise permite compreender como se constitui a dificuldade que $o$ estudante apresenta na sua aprendizagem. Essa análise passa a ser uma maneira de "tornar a avaliação mais informativa e imaginar melhor as condições didáticas e/ou pedagógicas adequadas para a superação do obstáculo revelado pelo erro" (HADJI, 2001, p. 101). Diante dessa compreensão, a correção não visa apenas a identificar quantos erros estão presentes na prova, mas quais erros e as razões que os causaram nas respostas dos alunos. $\mathrm{O}$ aluno também precisa ter esse mesmo entendimento sobre o erro para que possa desenvolver mecanismos para geri-los e avançar na aprendizagem.

Um exemplo favorável à correção e compreensão dos erros é o exercício da "coavaliação" ou avaliação entre pares - sugerido por vários autores. Ele favorece aos discentes a autoavaliação e o entendimento dos seus erros e falhas, pois, ao fazer a leitura do que o colega produziu, consegue pensar nas suas produções, dificuldades e aprendizagens. Villas Boas (2008, p. 94) sugere que "formas criativas de avaliar e usar a prova contribuem para a quebra de resistência dos alunos, principalmente de futuros educadores". A partir da adaptação das ideias da autora, sugere-se que, após os alunos responderem as questões da prova, eles recebam um quadro com os critérios de correção (já explicitados nas questões) e a prova de um colega que deverá ser analisada tendo como parâmetro os critérios estabelecidos, conforme exemplo do Quadro 1: 
QUADRO 1 - Critério de correções

\begin{tabular}{|c|c|c|}
\hline $\begin{array}{l}\text { CRITÉRIOS PARA } \\
\text { Nome do avaliado: }\end{array}$ & ORREÇÃO DAS QUES & DISSERTATIVAS: \\
\hline Nome do avaliador & & \\
\hline & ( ) SIM & JUSTIFIQUE: \\
\hline Respondeu o que & ( ) NÃO & \\
\hline é....? & ( ) PARCIALMENTE & \\
\hline O que faltou para a & questão ficar completa & \\
\hline Explicou ....? & ( ) SIM & JUSTIFIQUE: \\
\hline & ( ) NÃO & \\
\hline & ( ) PARCIALMENTE & \\
\hline O que faltou para a & questão ficar complet & \\
\hline Escreveu sobre ...? & ( ) SIM & JUSTIFIQUE: \\
\hline & ( ) NÃO & \\
\hline & ( ) PARCIALMENTE & \\
\hline O que faltou para a & questão ficar complet & \\
\hline Apresentou ...? & ( ) SIM & JUSTIFIQUE: \\
\hline & ( ) NÃO & \\
\hline & ( ) PARCIALMENTE & \\
\hline
\end{tabular}

Fonte: Elaboração da autora.

A proposta aqui apresentada toma como base o que sugeriu Perrenoud (1999, p. 99) ao defender a necessidade de pedagogias interativas e explicitar a necessidade de "colocar, tão frequentemente quanto possível em situações de confronto, de troca, de interação, de decisão, que os forcem a explicar, justificar, argumentar, expor ideias, dar e receber informações para tomar decisões”.

A etapa final de uma prova formativa difere-se totalmente da prova tradicional, pois enquanto esta consiste em apresentar ao estudante a prova corrigida que vai atestar seu desempenho por meio de uma nota, aquela se preocupa em fornecer um feedback informativo e em realizar exercícios de regulação planejados pelo docente na tentativa de recuperar as aprendizagens fragilizadas ou de alcançar as não aprendidas.

Em se tratando de uma prova formativa, Villas Boas (2008, p. 92) expressa que "cabe ao professor usar a prova com criatividade”, e sugere que, “após a realização, as provas 
são devolvidas para que, por meio de orientação de novos estudos, sejam revistas as respostas que demonstram essa necessidade".

Para que isso seja colocado em prática, pode-se pensar em entregar aos alunos, junto com a prova, um breve roteiro de perguntas que orientem a reflexão sobre as respostas e que favoreçam a autogestão dos erros, como os exemplos abaixo dos quadros $2,3,4,5$ e 6 :

QUADRO 2 - Roteiro de reflexão pós-correção de prova

EXEMPLO 1:

1. Avalie sua prova e emita um parecer. $O$ que esta prova significou para você? Como a fez? Qual a sua reflexão sobre os erros e acertos? Você consegue entender o que errou? A que conclusão pôde chegar?

2. Você considera que esta prova contribuiu para a sua aprendizagem? Ajudou a aprender mais ou não? Em que aspectos?

3. Sente que ainda está com dúvidas em relação ao que foi trabalhado até agora? Foi possivel perceber isso com a prova? Quais são suas maiores dificuldades? $\bigcirc$ que precisa fazer para avançar na aprendizagem?

4. Como você vê a PROVA hoje depois desta experiência?

5. Agora é a hora de você se autorregular. Retome cada questão e reflita sobre os erros apresentados e as anotações da professora, respondendo: o que faltou para sua resposta ficar completa? 0 que você acrescentaria? Apresentou erros? Em quê e por quê?

Fonte: Elaboração da autora. 
QUADRO 3 - Roteiro de reflexão pós-prova

\section{EXEMPLO 2:}

\section{Sobre a prova, responder:}

- Soube responder as questões adequadamente?

- Em que aspectos não correspondi ao solicitado?

- De que forma respondi a questão?

- O que deveria ter feito?

- Deveria ter acrescentado algo a mais?

- Confundi conceitos?

- O que fiz de errado?

- Ainda tenho dúvidas? Em quê?

Fonte: Elaboração da autora.

QUADRO 4 - Roteiro de reflexão sobre o conceito trabalhado EXEMPLO 3:

SOBRE O CONCEITO TRABALHADO

Soube elaborar o texto sobre

(apresentar o conceito)

O que poderia ter sido melhor?

Esqueci de explicar

Por que não consegui responder esta questão de acordo com o solicitado?

Minha resposta atendeu ao solicitado?

Entendi o significado desses conceitos?

Fonte: Elaboração da autora com base em Sanmartí (2009, p. 47).

\section{QUADRO 5 - Roteiro de reflexão sobre a aprendizagem}

\section{EXEMPLO 4:}

1. Realizar esta prova possibilitou-Ihe alguma aprendizagem? Por quê?

2. Após analisar a prova, a que conclusão pôde chegar em relação à sua aprendizagem?

3. O que considera ainda não ter aprendido? Qual a maior fragilidade que pôde observar em sua prova?

4. O que você vai fazer para aprender o que ainda falta? Como?

Fonte: Elaboração da autora. 
QUADRO 6 - Roteiro de feedback

\section{EXEMPLO 5:}

Em relação ao texto que escreveu, realize a seguinte tarefa:

Reveja o que está bom, o que faltou e o que precisa melhorar, refletindo sobre as seguintes questões:

- Quais são as fragilidades que o texto apresenta em termos de compreensão dos conceitos, estrutura, sequência e clareza de ideias?

- O feedback proporcionado pelo colega e pela professora ajudou-Ihe a perceber o que está bom, o que precisa melhorar e como fazer isso?

- O que poderia ter sido diferente?

- Depois de se autoavaliar, chegou a hora de se autorregular. Redija novamente um texto no qual vai apresentar a definição mais clara e coerente dos conceitos. Aproveite para compor um texto mais elaborado, e, para isso, pesquise em seu caderno, nos textos trabalhados e também em outras fontes.

Fonte: Elaboração da autora.

Essas e outras tarefas podem ser utilizadas como propostas para os alunos entenderem as falhas no caminho percorrido, as razões dos seus erros e assim buscar estratégias para superá-los.

Entende-se, assim, que a proposição de diferentes ações e encaminhamentos que levem em consideração a elaboração da prova com os critérios claros e bem definidos, uma correção preocupada em levantar dados para futuras intervenções, a compreensão diferenciada do erro, a proposição de feedback e de ações regulatórias por parte do docente, e ainda, a possibilidade de análise dos próprios erros que favoreça a autoavaliação e a autorregulação por parte do aluno, dão à prova caráter formativo.

\section{METODOLOGIA DE TRABALHO}

A pesquisa teve como objetivo principal investigar as diferentes possibilidades de uso da prova como instrumento de 
avaliação formativa na educação superior e com objetivos específicos: analisar as percepções dos discentes frente ao uso da prova como procedimento de avaliação formativa, perceber se a prova pode ir além da sua função comprobatória, verificar as etapas que esse instrumento deve percorrer para que se torne um instrumento formativo. Esta pesquisa é de natureza qualitativa e caracteriza-se como descritiva e explicativa, com elementos da análise do discurso.

A pesquisa foi desenvolvida na disciplina de Didática: Avaliação e Ensino na tentativa de encontrar uma alternativa didática para que os discentes de um curso de formação de professores tivessem a oportunidade de vivenciar uma experiência capaz de favorecer a superação de crenças relacionadas aos instrumentos avaliativos, especificamente em relação à prova escolar.

A prova seguiu o proposto para constituir um caráter formativo em todas as etapas. Após a correção, as provas foram entregues aos alunos sem menção de nota, apenas constavam anotações referentes às respostas, especificamente sobre sua qualidade, em relação àquilo que faltou para chegar ao mínimo necessário, bem como a percepção do docente sobre o caminho que o aluno percorreu.

$O$ trabalho posterior consistiu em uma conversa entre docente e discentes sobre cada questão da prova e ainda entre os próprios discentes para trocar e emitir opiniões relevantes sobre as respostas. Após esse momento, os alunos foram direcionados a realizar alguns exercícios regulatórios propostos pela docente. Aos alunos que apresentaram mais fragilidade em seus conhecimentos, foi proposto um estudo paralelo, que consistia na leitura de textos e tarefas. Esses exercícios regulatórios foram elaborados a partir da análise dos dados levantados na prova, com o propósito de ajudar o aluno a fazer um estudo sobre o caminho percorrido a fim de entender os equívocos e buscar alternativas para superar as dificuldades constatadas.

A pesquisa teve a participação de 29 discentes do segundo ano do curso de Pedagogia de uma instituição pública que realizaram a prova de caráter formativo. Ao final do trabalho, todos se dispuseram a responder um questionário com perguntas abertas que foi aplicado com o propósito de 
levantar dados sobre o significado da prova para os participantes, obter as contribuições para sua aprendizagem, formação e percepção em relação ao instrumento após a experiência.

\section{ANÁLISE E DISCUSSÃO DOS RESULTADOS}

Os dados coletados foram agrupados em categorias de análise, sendo que, em relação aos significados da prova para os participantes, foram identificados quatro itens que se revelam da seguinte forma: 1) diagnóstico das aprendizagens (31\%); 2) reflexão sobre os erros (31\%); 3) mudanças na concepção de avaliação (17\%); 4) autoavaliação (21\%).

A primeira categoria identificada foi o diagnóstico das aprendizagens. Para os discentes que assim a classificaram, isso se refere à prova como possibilidade de identificar os erros e reconhecer as maiores dificuldades sobre as aprendizagens. Como exemplos, seguem alguns depoimentos: "através da prova consegui identificar o que realmente aprendi e o que não aprendi" (aluno 7); "possibilitou constatar a minha maior dificuldade e perceber que preciso rever os conceitos." (aluno 19); "apontou um diagnóstico total do meu conhecimento sobre o assunto estudado" (aluno 8).

Ao possibilitar ao discente diagnosticar sua aprendizagem, entende-se que a prova cumpre sua função formativa, pois não é uma simples constatação do que sabe ou não sabe, mas uma tomada de consciência sobre a qualidade dessas aprendizagens e sobre a necessidade de uma ação para que as fragilidades sejam superadas. Perrenoud (1999, p. 68) afirma que uma avaliação formativa "identifica e explica erros, sugere interpretações quanto às estratégias e atitudes dos alunos”.

Quanto à segunda categoria, que se refere à reflexão sobre os erros, as palavras mais usadas revelam que isso ocorreu devido à forma como a prova foi corrigida - feedback escrito - e aos exercícios realizados após a entrega da prova. Tal significado está relacionado à possibilidade de entender e pensar sobre os erros de forma positiva, como expressam alguns discentes: "buscar o porquê desses erros"; "errei, mas aprendi"; "é errando que se aprende"; "sem as anotações, não teria entendido onde errei”. 
Os dados apresentados revelam que

[...] os alunos precisam de orientações sistemáticas e de avaliações do seu trabalho e dos seus desempenhos que os ajudem a melhorar as aprendizagens, que os estimulem e que os motivem a ir tão longe quanto possível, quer reconhecendo seus progressos e sucessos, quer ajudando a ultrapassar seus pontos fracos. (FERNANDES, 2009, p. 97)

Dessa forma, entende-se que oportunizar a reflexão sobre os erros favorece a sua compreensão como "objeto de estudo", possibilitando ao discente encontrar caminhos para a superação das falhas em sua aprendizagem.

A terceira categoria se apresenta como mudanças na concepção de avaliação. As palavras expressas pelos discentes revelam alterações no pensamento e no entendimento sobre o significado da prova e também da avaliação no contexto educativo. Os alunos afirmam que a experiência com a prova trouxe as seguintes contribuições para sua formação: mudança na visão sobre avaliação, compreensão sobre o papel do professor no processo avaliativo e a atribuição de um caráter diferenciado de correção e de intervenção. O depoimento a seguir apresenta algumas dessas contribuições:

Agora percebo que a avaliação da aprendizagem não é algo meramente técnico. Envolve autoestima, respeito à vivência e cultura própria do indivíduo, filosofia de vida e posicionamento político. Um professor que usa o erro do aluno para compreender o raciocínio do aluno e rever sua prática docente, se necessário, possui um posicionamento diferente daquele que apenas atribui zero pelo erro e continua dando suas aulas da mesma maneira. (aluna 26)

A aluna 13 também expressou uma concepção de avaliação que se apresenta como uma superação da visão tradicional ao afirmar que "a prova não foi um mero instrumento de classificação ou atribuição de nota, foi parte de um grande processo".

Mesmo apresentado por uma quantidade menor dos participantes (17\%), isso pode ser considerado positivo, pois é sabido que transformar as crenças já consolidadas é uma tarefa árdua e demorada, pois os sujeitos precisam de 
muitas certezas para deixar as crenças antigas e aventurar-se em novas. Em se tratando do processo avaliativo, isso se torna ainda mais difícil, já que os estudantes trazem as marcas das suas experiências vividas ao longo da sua trajetória acadêmica e, muitas vezes, saem da universidade e vão para os campos de atuação com as mesmas crenças que tinham inicialmente.

Para tanto, é no tempo e no espaço da formação que o futuro educador deve vivenciar inúmeras experiências que o ajudem a (re)construir novas crenças embasadas em conhecimentos científicos para que ele possa sair da universidade com concepções diferentes das de quando entrou.

A quarta categoria apresentada refere-se à autoavaliação. As evidências dessa categoria indicam que a autoavaliação foi possibilitada pelas anotações, correção, identificação dos erros e oportunidade de olhar a prova de outra maneira.

A prova, quando usada na perspectiva formativa, apresenta um significado diferente para o discente, a qual pode ir além de constatar um desempenho que será traduzido em valores numéricos, servindo para se autoavaliar e para aprender mais, conforme depoimento da aluna 23: “a prova significou a minha autoavaliação, pude ver onde errei, o que aprendi, o que faltou para aprender; tirei dúvidas que não consegui tirar nas aulas”. A aluna 19 expressa: “com essa prova, pude me autoavaliar através dos erros e das anotações. Agora sei com certeza o que tenho que rever e estudar para corrigir meus erros".

Em relação às contribuições que a prova possibilitou para a aprendizagem, todos os alunos (100\%) afirmaram que a experiência foi positiva, principalmente pela possibilidade de "aprender os conceitos", "apontar os principais erros”, "tirar dúvidas", "perceber que não tinha aprendido tudo", "revisar conceitos". As palavras apontam indicadores para a autorregulação como categoria eleita nesta análise.

As alunas 6, 7 e 29 demonstram ter-se autorregulado ao expressarem: "a prova possibilitou ver que não assimilei totalmente os conteúdos, pois antes, nas aulas, pensava que entendia tudo. Agora vou estudar novamente os conceitos que ficaram confusos e prestar mais atenção ao escrever" 
(aluna 6). "Através da prova, consegui perceber que confundo conceitos e consegui verificar que, com um pouco mais de atenção e reflexão, saberia responder as questões" (aluna 7); "a prova contribuiu para perceber que devo manter a leitura e a atenção, pois, como me preocupo com as questões que não consigo resolver, acabo cometendo erros por falta de atenção" (aluna 29).

A autorregulação possibilita ao aluno gerir seus próprios erros e entender os caminhos a serem percorridos sem a necessidade de intervenção constante do professor. Ele mesmo consegue refletir e tomar as decisões em relação ao que precisa ser feito. Para exercitar a autorregulação, o aluno precisa ter, segundo Jorba e Sanmartí (2013), clareza e conhecimento dos seguintes aspectos: objetivos, planejamento das ações e critérios de avaliação.

No que se refere aos objetivos, é imprescindível que o aluno saiba o propósito de determinada tarefa ou discussão sobre certo assunto e do aprendizado de determinado conteúdo. Dessa forma, terá condições de saber o que se espera dele e os caminhos que serão percorridos, bem como onde se pretende chegar. $O$ planejamento das ações refere-se ao exercício de pensar antes de agir, ou seja, o aluno não apenas realiza uma tarefa ou responde uma questão, mas passa a organizar uma forma de realizá-la. Com frequência, os discentes executam o que lhes é solicitado de forma imediata e sem o cuidado de organizar sua ação, o que pode comprometer seu trabalho. Nesse caso, o professor exerce um papel importante que é o de possibilitar experiências que levem o aluno ao aprendizado de diferentes estratégias ao ajudá-lo a resolver as tarefas propostas pela docente. Outro aspecto importante é a compreensão dos critérios de avaliação, os quais precisam estar explícitos para que os alunos entendam o que o professor quer deles no momento avaliativo.

Sobre a percepção em relação ao instrumento após a experiência, as respostas dos alunos apresentam um entendimento da prova como um "momento de aprendizagem" que, mais do que medir o quanto o aluno aprendeu, revela como ele aprendeu, conforme depoimentos: "agora entendo a prova como algo que me ajuda a melhorar e a buscar mais 
conhecimento, que ajuda a me avaliar e a crescer como aluna e futura professora" (aluna 3); "diferente do que pensava antes, entendo a prova agora como um momento em que posso aprender mais, pois pude detectar minhas dificuldades e perceber o que preciso fazer para saná-las” (aluna 17).

Diante dos resultados, entende-se que a prova pode ser utilizada como ferramenta de avaliação formativa, superando o paradigma da classificação. Para tanto, se faz necessária a compreensão do significado da avaliação em tal perspectiva e levar em consideração que avaliar vai muito além de preparar uma prova, aplicar, corrigir, registrar a nota e entregá-la ao aluno para que ele resolva o que fazer diante dos resultados. Cumpre afirmar que avaliar, em uma concepção formativa, requer dos docentes e discentes disposição, compreensão do papel da avaliação no contexto escolar, superação do entendimento do erro enquanto sinônimo de fracasso e incompetência e ação diante dos resultados que não corresponderam ao esperado.

\section{CONSIDERAÇÕES FINAIS}

Diante dos dados apresentados e analisados, entende-se que a prova cumpriu seus objetivos enquanto ferramenta de avaliação formativa, pois apresentou diferentes significados para os alunos que os ajudaram a se autoavaliar, a entender as razões dos seus erros, a ter uma dimensão da qualidade das aprendizagens e alguns indícios de mudança de concepção da avaliação.

Os resultados também revelaram contribuições no que se refere à aprendizagem e ao entendimento positivo da prova após a experiência, tendo em vista que o feedback e a realização de uma atividade posterior ao recebimento da prova conduziram os alunos ao exercício da autorregulação e os auxiliou no avanço da autonomia. A possibilidade que os discentes tiveram de rever os erros, refletir sobre os mesmos e perceber os caminhos que poderiam percorrer para a sua superação foi outra oportunidade significativa que os ajudou a desmistificar a prova como instrumento classificatório.

Assim, novas compreensões foram construídas em relação ao uso desse instrumento e em relação às possibilidades 
que ele pode oferecer para auxiliar professor e alunos no processo de construção de aprendizagens mais significativas e superação dos obstáculos identificados e que atrapalham o avanço do processo.

Ao refletir sobre o estudo realizado, é possível inferir que uma prova formativa não é uma tarefa simples e rápida a ser cumprida e que também não é a solução dos problemas pedagógicos na universidade, mas pode ser entendida como uma alternativa para outros caminhos em relação ao ensino universitário, possibilitando novas experiências para seus estudantes nesse processo de formação docente e para o repensar das políticas de formação inicial e continuada de professores.

\section{REFERÊNCIAS}

AFONSO, Almerindo Janela. Avaliação educacional: regulação e emancipação - para uma sociologia das políticas avaliativas contemporâneas. 3. ed. São Paulo: Cortez, 2005.

ALLAL, Linda. Estratégias de avaliação formativa: concepções psicopedagógicas e modalidades de aplicação. In: ALLAL, Linda; CARDINET, Jean; PERRENOUD, Philippe. A avaliação formativa num ensino diferenciado. Coimbra: Livraria Almedina, 1986. p. 175-209.

ÁLVAREZ MÉNDEZ, Juan Manuel. Avaliar para conhecer - examinar para excluir. Porto Alegre: Artmed, 2002.

CARDINET, Jean. Avaliar é medir? Coimbra: Edições Asas, 1993.

COIMBRA, André Luiz Martins. Revendo a avaliação dos repetentes na universidade. In: FELTRAN, Regina Célia de Santis. (Org.). Avaliação na educação superior. São Paulo: Papirus, 2002. p. 67-82.

DEPRESBÍTERES, Léa; TAVARES, Marialva Rossi. Diversificar é preciso...: instrumentos e técnicas de avaliação da aprendizagem. São Paulo: Editora Senac, 2009.

ESTEBAN, Maria Teresa (Org.). Avaliação: uma prática em busca de novos sentidos. 3. ed. Rio de Janeiro: DP\&A, 2001.

FERNANDES, Domingos. Avaliar para aprender: fundamentos, práticas e políticas. São Paulo: Editora Unesp, 2009.

HADJI, Charles. A avaliação, as regras do jogo. Das intenções aos instrumentos. Porto: Porto, 1994. Avaliação desmistificada. Porto Alegre: Artmed, 2001. 
JORBA, Jaume; SANMARTÍ, Neus. A função pedagógica da avaliação. In: BALLESTER, Marguerita et al. Avaliação como apoio à aprendizagem. Porto Alegre: Artmed, 2003. p. 23-45.

LUCKESI, Cipriano Carlos. Avaliação da aprendizagem escolar. 12. ed. São Paulo: Cortez, 2002.

MASETTO, Marcos Tarcísio. Competência pedagógica do professor universitário. São Paulo: Summus, 2003.

MORAES, Dirce Aparecida Foletto de. Avaliação formativa: re-significando a prova no cotidiano escolar. 2008. 148 f. Dissertação (Mestrado em Educação) - Universidade Estadual de Londrina, Londrina, Paraná. 2008.

. Prova: instrumento de avaliação formativa a serviço da regulação do ensino e da aprendizagem. Estudos em Avaliação Educacional, São Paulo, v. 22, n. 49, p. 233-258, maio/ago. 2011.

PERRENOUD, Philippe. Avaliação: da excelência à regulação das aprendizagens. Porto Alegre: Artmed, 1999.

QUINTANA, Hilda. O portfólio como estratégia para a avaliação. In: BALLESTER, Marguerita et al. Avaliação como apoio à aprendizagem. Porto Alegre: Artmed, 2003. p. 163-173.

SACRISTÁN, José Gimeno. Compreender e transformar o ensino. Porto Alegre: Artmed, 2000.

SANMARTÍ, Neus. Avaliar para aprender. Porto Alegre: Artmed, 2009.

SORDI, Mara Regina Lemes; SILVA, Margarida Montejano. O uso de portfólios na pedagogia universitária: uma experiência em cursos de enfermagem. Revista Interface. Comunicação Saúde Educação, v. 14, n. 35, p. 943-953, out./dez. 2010. Disponível em: <http://www.scielo.br/pdf/icse/2010nahead/aop1910.pdf> . Acesso em: 18 ago. 2011.

VILLAS BOAS, Benigna Maria de Freitas. Virando a escola do avesso por meio da avaliação. Campinas: Papirus, 2008.

DIRCE APARECIDA FOLETTO DE MORAES

Doutoranda em Educação pela Universidade Estadual

Paulista "Júlio de Mesquita Filho", campus Presidente Prudente (Unesp). Professora do Departamento de Educação da Universidade Estadual de Londrina (UEL/PR) dircemoraes@uel.br 
